\title{
Polarized light scattering by aerosols in the marine atmospheric boundary layer
}

\author{
Mary S. Quinby-Hunt, Lael L. Erskine, and Arlon J. Hunt
}

\begin{abstract}
The intensity and polarization of light scattered from marine aerosols affect visibility and contrast in the marine atmospheric boundary layer (MABL). The polarization properties of scattered light in the MABL vary with size, refractive index, number distributions, and environmental conditions. Laboratory measurements were used to determine the characteristics and variability of the polarization of light scattered by aerosols similar to those in the MABL. Scattering from laboratory-generated sea-salt-containing (SSC) $\left[\mathrm{NaCl},\left(\mathrm{NH}_{4}\right)_{2} \mathrm{SO}_{4}\right.$, and seawater] components of marine aerosols was measured with a scanning polarization-modulated nephelometer. Mie theory with Gaussian and log normal size distributions of spheres was used to calculate the polarized light scattering from various aerosol composition models and from experimentally determined distributions of aerosols in the marine boundary layer. The modeling was verified by comparison with scattering from distilled water aerosols. The study suggests that polarimetric techniques can be used to enhance techniques for improving visibility and remote imaging for various aerosol types, Sun angles, and viewing conditions. (c) 1997 Optical Society of America

Key words: Marine atmospheric boundary layer, polarization, light scattering, aerosols.
\end{abstract}

\section{Introduction}

Aerosols in the marine atmospheric boundary layer (MABL) affect visibility, cloud formation, radiative transfer, and the heating and cooling of the Earth. Dense MABL hazes modify the propagation of sunlight affecting the intensity and polarization of light reaching the sea surface. Both of these quantities must be included for radiant transfer calculations at the surface of and within the ocean. ${ }^{1,2}$ Aerosols in the MABL affect visibility because they scatter sunlight or moonlight into the object-viewer (targetdetector) path, which reduces the contrast between the viewed scene and the background, thereby diminishing visibility. Near-forward scattered light from the Sun is most effective in reducing contrast of a naturally lighted scene and is dominated by the large particles in the aerosol (Fig. 1a). If the scene is illuminated by a source above or behind the detector, backscattered light is most important in reducing

M. S. Quinby-Hunt and A. J. Hunt are with the Energy and Environment Division, Lawrence Berkeley National Laboratory, University of California, 1 Cyclotron Road, Berkeley, California 94720. L. L. Erskine is with the California Institute of Technology, Pasadena, California 91125.

Received 9 September 1996; revised manuscript received $10 \mathrm{Feb}-$ ruary 1997.

0003-6935/97/215168-17\$10.00/0

(C) 1997 Optical Society of America contrast (Fig. 1b). Since this scattering can occur at any angle, it can be caused by particles of nearly any size. Thus, depending on the situation, aerosol particles of all sizes are important in determining visibility.

Particle size not only affects the intensity of scattered light but also its polarization properties. If the polarization of light scattered from an object differs from that of light scattered from the interposed medium, contrast between object and medium may be improved. ${ }^{3}$ Polarized light has been used to improve image contrast in underwater viewing systems. ${ }^{3-6}$ Briggs and Hatchett ${ }^{4}$ found that the use of linearly polarized light improved visibility by $20 \%$ in muddy waters. The use of circularly polarized incident light improves underwater contrast. 7,8

The angular dependence of the linear and circular polarization of light scattered by the MABL depends on the size distribution, complex refractive indices, shape, and orientation of the particles making up an aerosol. As aerosols may be homogeneous or inhomogeneous and of varying size, composition, real and imaginary refractive indices, and shape, the resultant polarization from different aerosols may vary dramatically. Because the polarization properties of an aerosol can affect visibility, light propagation, and radiant transfer in the MABL, it is important to quantify the effect and its variability. It is then possible to explore how polarimetry can be used to enhance visibility and discrimination in the MABL, 

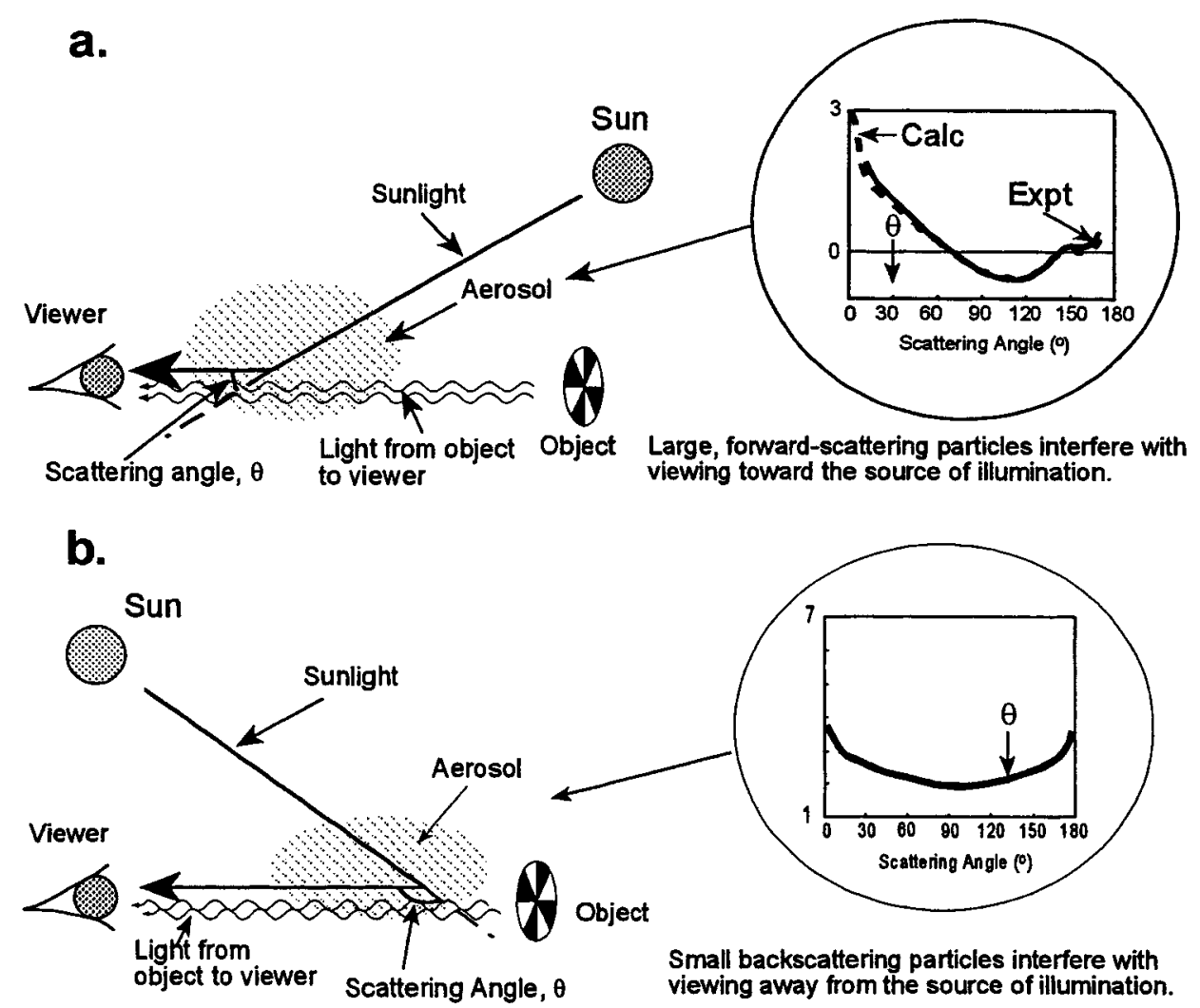

Fig. 1. Effect of aerosols on visibility. a, The pronounced forward scattering of large aerosol particles scatter sunlight (or moonlight) into the viewer-object plane when the Sun is behind the viewed object. Scattering plotted in the inset is the angular distribution of the total intensity (phase function) of light $\left(\lambda=532 \mathrm{~nm}\right.$ ) scattered by a seawater aerosol with a $r_{\text {mode }} \sim 0.7 \mu \mathrm{m}$ and relative refractive index of $1.34-$ $0 i$. Both experimental data and calculation are shown. b, When particles are very small relative to the wavelength of light, the proportion of backscattered light relative to forward scattering is significant as is shown in the inset. (Scattering predicted for an aerosol with particles of $r_{\text {mode }} \sim 0.03 \mu \mathrm{m}$, relative refractive index of $1.335-0 i$, and $\lambda=532 \mathrm{~nm}$.) In this case light is scattered into the viewer-object plane when the Sun (or Moon) is above or behind the viewer.

given the variability of scattering by different aerosols.

The limited research on the scattering properties of atmospheric aerosols has been primarily with terrestrial aerosols. ${ }^{9-11} \quad$ Few studies have investigated the polarization properties of scattered light in marine aerosols ${ }^{10,11}$ and even fewer have used the fullest description of the polarization as embodied by the Mueller scattering matrix formalism. ${ }^{12-14}$ This formalism presents all the available polarization information of the scattered light as a function of angle. Past measurements of the polarization properties of atmospheric aerosols have been limited, and most of those have involved lidar measurements that did not treat angle dependence.

Hansen and Evans ${ }^{15}$ presented angle-dependent measurements of four elements of the Mueller matrix. These measurements were taken on urban aerosols drawn into a laboratory nephelometer and presented without normalization or phase information. Unnormalized scattering signals from aerosols typically range over many orders of magnitude because of the variation in the scattering phase function and scattering volume. The large changes in intensity tend to mask any polarization dependence, mak- ing it difficult to gauge its behavior. If the polarization signal is normalized by dividing the signal by the total intensity, fluctuations in polarization are revealed. Phase information should be accounted for so that the sign of the polarization (direction) as the signals pass through zero is retained. Therefore it is important to normalize by the total intensity and essential to keep track of the phase to determine the sense or direction of the polarization.

This paper explores the effect of a variety of aerosols on polarized light scattering in the MABL. The polarized light scattering due to typical marine aerosols was calculated with a commonly used model for marine aerosol composition and size. The effect of humidity on scattering was investigated both with the model and experimentally. To verify the hypothesis that polarization properties of light scattered from the sea-salt containing (SSC) component of the aerosols in the MABL will change dramatically with humidity, laboratory experiments were conducted with aerosols of distilled water, several salts, and seawater. To investigate the effect of addition of smoke, a common pollutant frequently found in the MABL, calculated scattering from smokes was com- 
Table 1. Input Parameters for the AFGL Model for Marine Aerosols ${ }^{a}$

\begin{tabular}{cccccc}
\hline & $\begin{array}{l}r_{\text {mode }} \\
(\mu \mathrm{m})\end{array}$ & $\begin{array}{c}r_{\text {min }} \\
(\mu \mathrm{m})\end{array}$ & $\begin{array}{c}r_{\max } \\
(\mu \mathrm{m})\end{array}$ & $\sigma$ & $n$ \\
\hline Component 1: & \multicolumn{7}{c}{ small aerosol component } \\
$50 \% \mathrm{RH}$ & 0.027 & 0.005 & 0.2 & 0.35 & $1.52-0.006 i$ \\
$80 \% \mathrm{RH}$ & 0.033 & 0.006 & 0.2 & 0.35 & $1.44-0.004 i$ \\
$99 \% \mathrm{RH}$ & 0.053 & 0.009 & 0.2 & 0.35 & $1.36-0.001 i$ \\
Component $2:$ & maritime component & & \\
$50 \% \mathrm{RH}$ & 0.2 & 0.03 & 1.5 & 0.4 & $1.47-0 i$ \\
$80 \% \mathrm{RH}$ & 0.35 & 0.04 & 2.5 & 0.4 & $1.355-0 i$ \\
$99 \% \mathrm{RH}$ & 0.76 & 0.10 & 3.5 & 0.4 & $1.34-0 i$ \\
\hline
\end{tabular}

${ }^{a}$ Ref. 25.

bined with that from the predicted by the marine component models.

Aerosols in the MABL. The character of aerosols in the MABL is determined by the physical, chemical, and biological conditions of the underlying ocean, meteorological conditions (temperature, humidity, wind, and cloud cover), anthropogenic sources, and terrestrial (both natural and anthropogenic) inputs. Marine sources include condensed water vapor and condensed gases from biological ocean sources, aqueous salt aerosols from the wind-sea interface, and settling from the troposphere. Under normal conditions the main constituents of aerosols over the ocean include water, sea salt, non-sea-salt (nss) sulfate, mineral dust, and a small fraction of nitrates and organic matter. ${ }^{10,11,16-23}$

The sea-salt component is believed to compose the coarser fraction ( $r_{\text {mode }}$ generally $>0.3 \mu \mathrm{m}$ ) of the aerosols, ${ }^{11,24}$ while nss sulfates, continental aerosols, and organic matter contribute to the smaller fractions. (In this paper, the size distributions used are number distributions unless otherwise noted; the term $r_{\text {mode }}$ refers to the radius of the particles whose number density is greatest in a log normal distribution.) The size distribution of the smaller, nss marine aerosols in the MABL has been described as bimodal. The smallest particles $\left(r_{\text {mode }} \sim 0.03 \mu \mathrm{m}\right)$ are thought to be gas-phase reaction products such as $\mathrm{H}_{2} \mathrm{SO}_{4}$, $\mathrm{H}_{2} \mathrm{~S}$, continentally derived aerosols, ${ }^{25}$ or $\left(\mathrm{NH}_{4}\right)_{2} \mathrm{SO}_{4}$ possibly derived from marine-generated dimethyl sulfide. ${ }^{26-28}$

The coarse $\left(r_{\text {mode }}>0.3 \mu \mathrm{m}\right)$ fraction, primarily the SSC component, of marine aerosols is produced primarily by bubble bursting and wave sheering. ${ }^{29}$ Bubble bursting forms droplets, film drops, and jet drops. ${ }^{24}$ Film drops are smaller than jet drops, producing droplets with radii roughly less than $1 \mu \mathrm{m}$; those produced by jet drops are generally greater than $1 \mu \mathrm{m} .{ }^{16}$ Neither will be found more than a few millimeters from the surface unless wind advects them higher into the air; however, these droplets are often advected to as high as $2 \mathrm{~km}$ above the surface. ${ }^{16,24}$ Wave-sheering wind causes drops to advect into the air directly off the wave. ${ }^{30}$ SSC aerosol particles with significant water content are generally spherical.

The size of aerosol particles depends on particle growth, gravity, humidity, and precipitation scavenging. 10,31-33 Humidity is particularly important for hygroscopic particles and can affect the size of a particle by evaporation from or absorption of water by the particle. ${ }^{25,32}$ Relative humidity can increase or decrease particle size and may also change the shape and homogeneity of the particle. ${ }^{34}$ The size distribution of the coarse fraction thus depends strongly on wind speed and weather conditions, as both bubble bursting and wave sheering depend on white-cap cover. ${ }^{24,30,33}$ Thus SSC particles are more likely to be generated in stormy conditions or conditions with higher winds. ${ }^{33,35}$ As larger particles settle out more rapidly than smaller particles, even within the coarse fraction smaller particles form a more stable population than do large particles.

To date, the vast majority of aerosol studies identify and characterize the components of marine aerosols through examination of the morphology of collected particles. In laboratory studies with SSC component aerosols and in field observations, Mészáros and Vissy ${ }^{26}$ found particles whose morphology indicated that they were mixtures of various seawater components that, as they dried, crystallized into different forms. The issue for understanding the polarization of light scattering in the MABL is the shape and size of the components in situ. Any collection technique perturbs the natural conditions. Even instruments that determine size based on scattering techniques rely on a number of assumptions regarding symmetry of the particles and refractive indices.

Thus it is important to develop methods to characterize polarized light scattering without collection. As part of this effort, we have measured polarization properties of angle-dependent light scattering of water, seawater, $\mathrm{NaCl}$, and $\left(\mathrm{NH}_{4}\right)_{2} \mathrm{SO}_{4}$ aerosols in the laboratory to investigate how humidity affects their polarization properties and to demonstrate the variability in polarization properties that might be observed in the MABL.

Experimental Measurements of Particle Distributions in the MABL. A number of researchers (see the review article by Fitzgerald ${ }^{11}$ ) have examined the particle size distributions in the MABL with various sampling and collection devices, both at sea (for example, Ref. 10) and in the coastal zone. ${ }^{23}$ Most report the predominance of the small component(s) with $r_{\text {mode }} \sim 0.03 \mu \mathrm{m}$, in agreement with the U.S. Air Force Geophysics Laboratory (AFGL) ${ }^{25}$ and U.S. Na$v^{36}$ models, and a second component with a somewhat larger $r_{\text {mode }}$, generally in the range of $0.09-0.15$ $\mu \mathrm{m}$, which is somewhat smaller than that used in the AFGL and Navy models. The coarse SSC fraction is additional. The size distributions vary considerably on the basis of humidity, wind speed, and proximity to land. ${ }^{10}$

Models of Aerosols in the MABL. A number of models have been developed to describe the size and composition of marine aerosols. Some are relatively simple, such as those of Diermendjian, ${ }^{12}$ involving a gamma distribution of a single compo- 

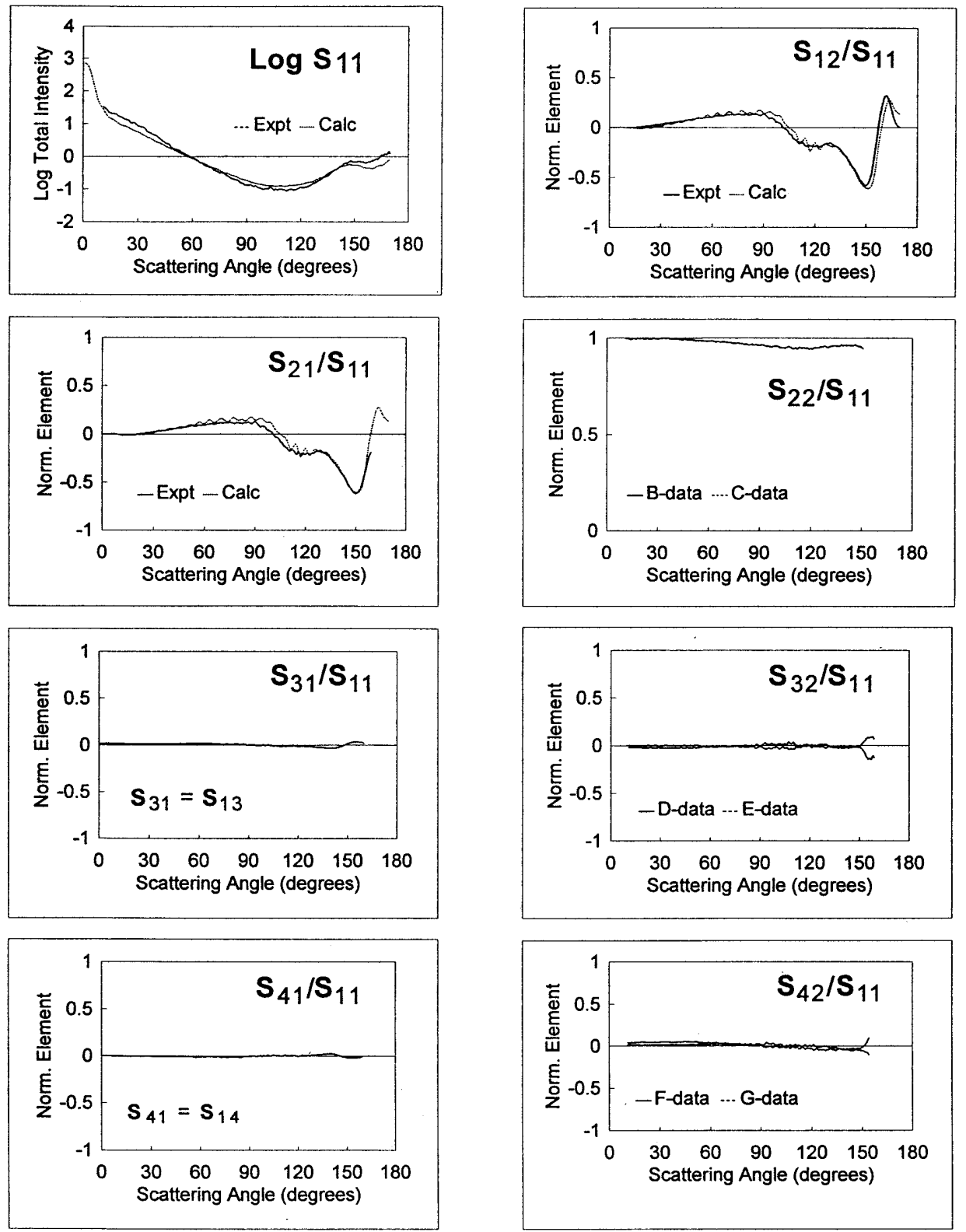

(a)

Fig. 2. Comparison of the measured and the calculated angle dependences of all 16 elements of the Mueller scattering matrix for a distilled water aerosol. Calculations indicate that the $r_{\text {mode }}$ is $1 \mu \mathrm{m}$ and the refractive index is $1.33-0 i$ at a wavelength of $532 \mathrm{~nm}$. For some of the elements multiple data sets are shown; agreement is excellent. Calculations are only made for $S_{11}, \mathbf{S}_{12}=\mathbf{S}_{21}, \mathbf{S}_{33}=\mathbf{S}_{44}$, and $\mathbf{S}_{34}=-\mathbf{S}_{43} . \quad \mathbf{S}_{22}$ is 1 , and all other elements are zero by symmetry. These relationships are borne out by the experimental observations. (a) Mueller matrix elements from the first two columns of the matrix.

nent. One commonly employed model is that developed by Shettle and Fenn, ${ }^{25}$ the AFGL model. For marine aerosols the model sums log normal distributions of two components. The actual size distribution of each component varies, depending on the source and relative humidity $(\mathrm{RH})$. In this model, for the smaller component they use the same characteristics as their "rural, terrestrially derived aerosol mixture," which is a "combination of soluble and insoluble matter," both with $r_{\text {mode }} \sim 0.03 \mu \mathrm{m}$. Approximately $70 \%$ of the combination is water soluble $\left[\left(\mathrm{NH}_{4}\right)_{2} \mathrm{SO}_{4}, \mathrm{CaSO}_{4}\right.$, and organic matter], and
$30 \%$ is dustlike aerosols. The second component, which they call the maritime component, is primarily a sea-salt mixture $\left(r_{\text {mode }} \sim 0.3 \mu \mathrm{m}\right.$ at $\left.80 \% \mathrm{RH}\right)$. The size of the particles making up each component varies with $\mathrm{RH}$, based on Hänel's formulation. ${ }^{32}$ The refractive index for water was based on the survey by Hale and Querry. ${ }^{37}$ For the refractive index of sea salt, Shettle and Fenn reference the work by Volz ${ }^{38}$ and Dorsey, ${ }^{39}$ which at $0 \% \mathrm{RH}$ is slightly less than that reported for $\left(\mathrm{NH}_{4}\right)_{2} \mathrm{SO}_{4}$ by Perry et al. ${ }^{14}$ At higher $\mathrm{RH}$ the refractive index is a weighted average of the refractive indices of water 

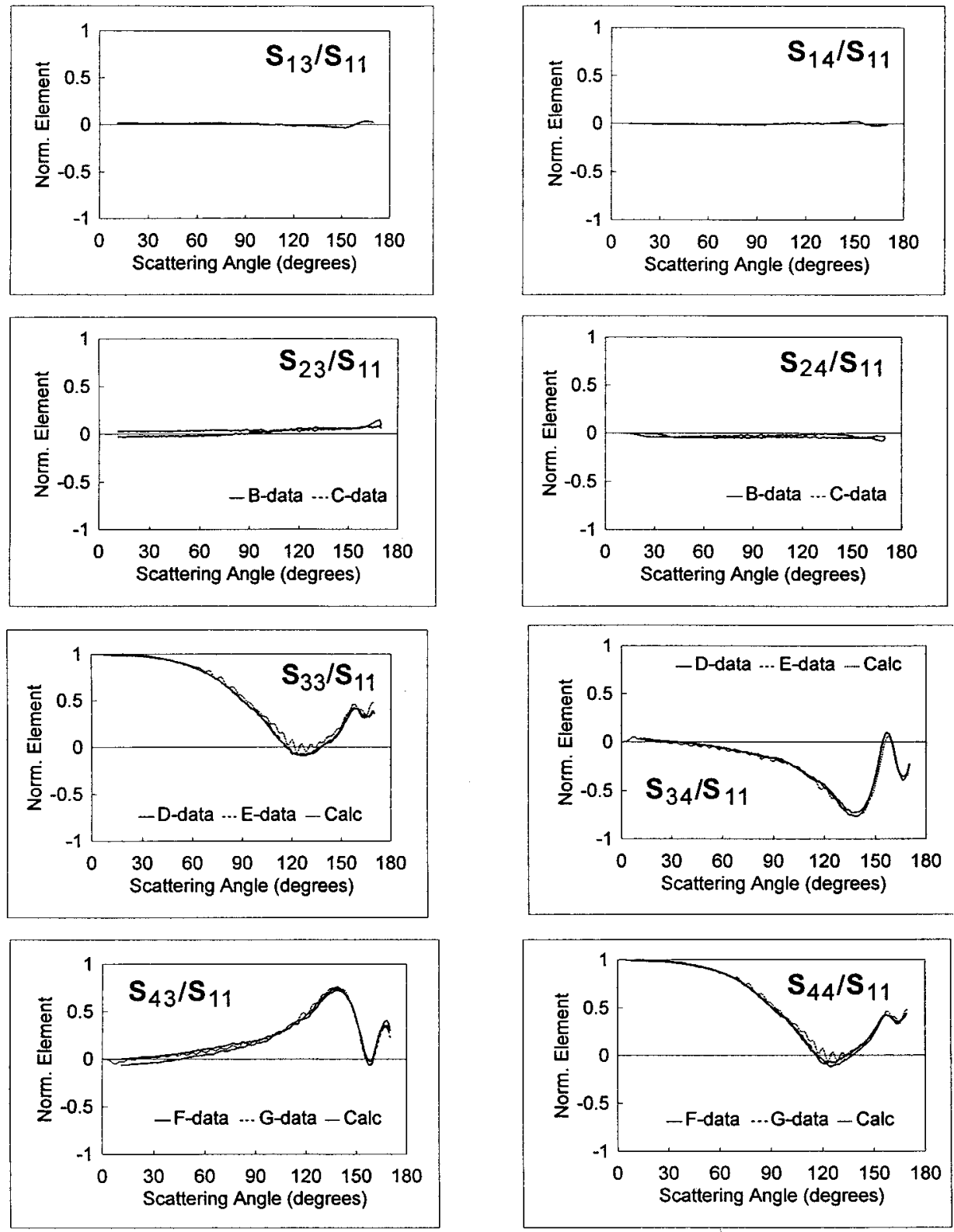

(b)

Fig. 2. Continued from facing page. (b) Mueller matrix elements for the third and fourth columns of the matrix.

and sea salt. Each component is treated as a log normal distribution of single spherical scatterers. Table 1 presents the size, standard deviation $\sigma$, and refractive index $\mathbf{n}$ for a marine aerosol based on this model at a wavelength of $514 \mathrm{~nm}$. The AFGL model weights the number density of the smaller component as 0.999875 and the larger component as 0.000125 .

The more recent Navy Oceanic Vertical Aerosol Model developed by Gathman and Davidson ${ }^{36}$ uses a four-component system, which is a sum of four log normal distributions. This model, not used here, introduces a greater complexity to modeling aerosols in the MABL.

\section{Polarized Light Scattering of Marine Aerosols: Theory and Hypothesis}

The intensity and polarization of light are described $^{40,41}$ by a four-element Stokes vector defined in terms of the complex electric fields $E_{l}$ and $E_{r}$ parallel and perpendicular to the scattering plane:

$I$ is the total intensity of light, $\left\langle E_{l} E_{l}{ }^{*}+E_{r} E_{r}{ }^{*}\right\rangle$; $Q$ is $\pm 90^{\circ}$ polarization, $\left\langle E_{l} E_{l}{ }^{*}-E_{r} E_{r}{ }^{*}\right\rangle$;

$U$ is $\pm 45^{\circ}$ polarization, $\left\langle E_{l} E_{r}{ }^{*}+E_{r} E_{l}^{*}\right\rangle$;

$V$ is circular polarization, $\left\langle i\left(E_{l} E_{r} *-E_{r} E_{l}^{*}\right)\right\rangle$.

(The angle brackets indicate time averages, and the asterisks denote complex conjugates.) The scatter- 


\section{a. Scanning polarization-modulated nephelometer}

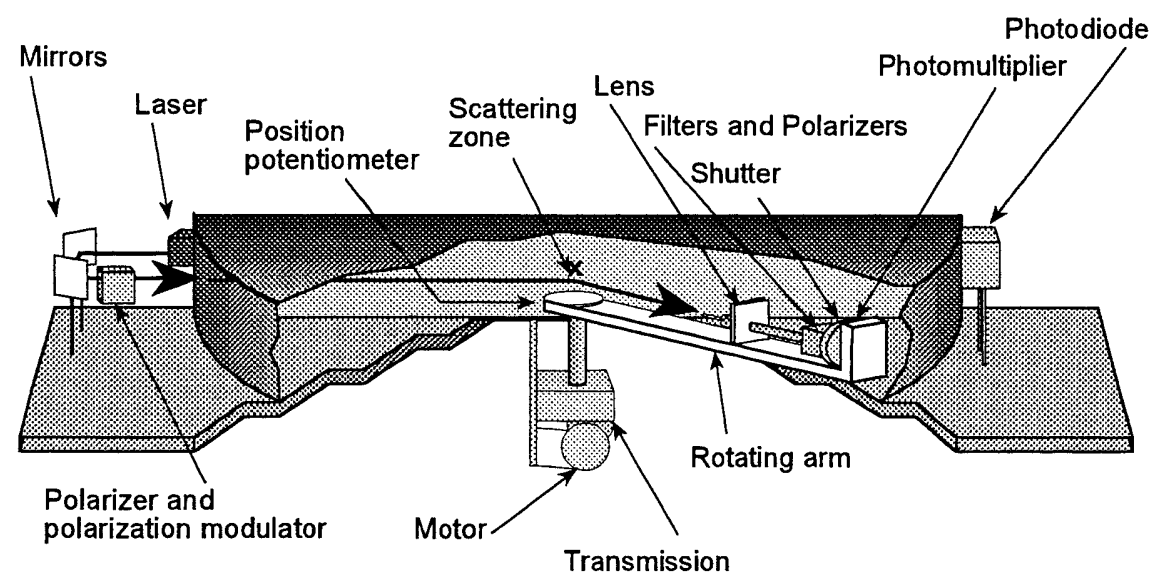

\section{b. Nebulizer-desiccation system with focussing element in delivery attachment}

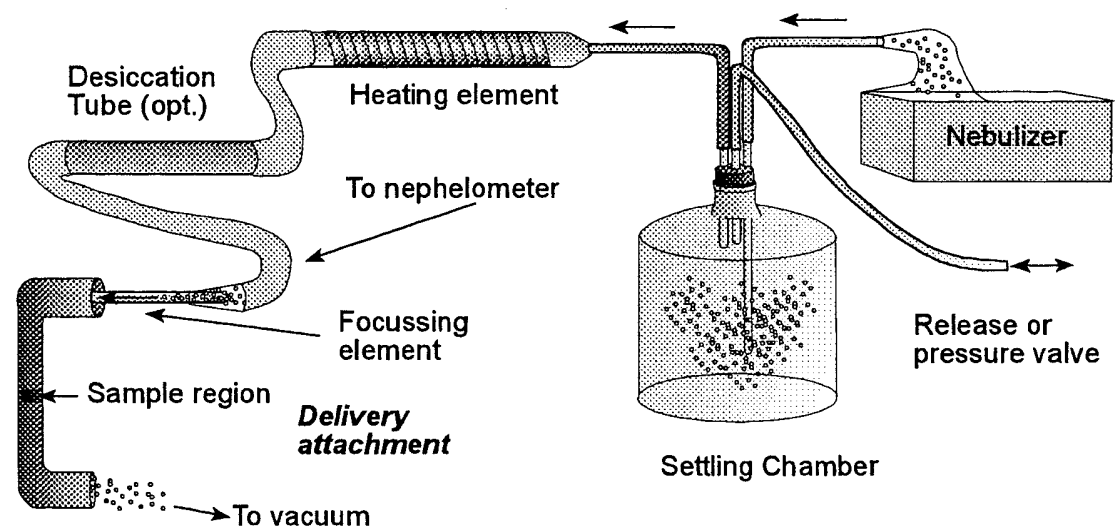

Fig. 3. Experimental apparatus. a, Scanning polarization-modulated nephelometer as designed by Hunt ${ }^{52}$ and Hunt and Huffman. ${ }^{53}$ $\mathrm{b}$, Aerosols pass from the nebulizer-desiccation system into the focusing element in the delivery attachment at the focus of the scattering zone of the nephelometer.

ing of light is described by a transformation of the Stokes vector by a $4 \times 4$ Mueller matrix. The Mueller matrix associated with a particular suspension of marine aerosol particles can be used to describe and quantify the effects that the suspension will have on scattered light in the MABL. In general, eight of the elements of the Mueller matrix (normalized by the total intensity; designated $S_{x y} / S_{11}=\mathbf{S}_{x y}$ ) are nonzero for spherical aerosols: $S_{11}, \mathbf{S}_{12}=\mathbf{S}_{21}, \mathbf{S}_{22}, \mathbf{S}_{33}, \mathbf{S}_{44}$, and $\mathbf{S}_{34}=-\mathbf{S}_{43}$. This simplification is based on symmetry considerations. ${ }^{40}$ Other elements might be nonzero due to particle chirality or alignment of nonspherical aerosols.

The polarization properties of the larger marine aerosols $\left(r_{\text {mode }}>0.3 \mu \mathrm{m}\right)$ can be predicted with Mie theory as long as the particles are nearly spherical.
The sphericity of these particles depends on $\mathrm{RH}$ and composition. Measurements and calculations with Mie theory have shown that fogs and hazes are well approximated as an ensemble of spheres. ${ }^{42}$ The SSC component of marine aerosols is hygroscopic, meaning that their size and shape are influenced by $\mathrm{RH}$. One can readily hypothesize that in high humidity, the SSC component of a marine aerosol is spherical. If this hypothesis is true, then the effect of these particles on the polarization of light they scatter can be calculated rigorously. Whereas some sulfates appear to form spherical particles, dry $\mathrm{NaCl}$ aerosols are cubical, and the scattering from ensembles of NaCl crystals, roughly the size of the sea-salt component, deviates significantly from that predicted for spheres. ${ }^{14}$ 
Table 2. Experimental Conditions and the Calculated Radius at the Peak of the Size Distribution $r_{\text {mode }}$ and Complex Refractive Index

\begin{tabular}{|c|c|c|c|}
\hline Component & $\begin{array}{c}\text { Temperature } \\
\left({ }^{\circ} \mathrm{C}\right)\end{array}$ & $\begin{array}{c}r_{\text {mode }} \\
{\left[r_{\max }-r_{\min }\right]} \\
(\mu \mathrm{m})\end{array}$ & $\begin{array}{c}\text { Complex } \\
\text { Refractive } \\
\text { Index }\end{array}$ \\
\hline Pure water & 20 & $1.00[0.75-2.75]$ & $1.335-0 i$ \\
\hline \multirow[t]{6}{*}{$\mathrm{NaCl}$} & 20 & $0.77[0.35-2.35]$ & $1.34-0 i$ \\
\hline & 34 & $0.72[0.5-2.0]$ & $1.345-0 i$ \\
\hline & 46 & $0.57[0.05-1.95]$ & $1.35-0 i$ \\
\hline & 70 & $0.57[0.05-1.95]$ & $1.35-0 i$ \\
\hline & 100 & $0.42[0.05-1.45]$ & 1.36 \\
\hline & 105 & $a$ & $a$ \\
\hline \multirow[t]{3}{*}{$\left(\mathrm{NH}_{4}\right)_{2} \mathrm{SO}_{4}$} & 20 & $0.72[0.5-2.0]$ & $1.34-0 i$ \\
\hline & 85 & $0.42[0.05-1.45]$ & $1.35-0 i$ \\
\hline & 178 & $0.23[0.05-1.5,]^{b}$ & $1.48-0 i^{b}$ \\
\hline \multirow[t]{5}{*}{20} & & $0.72[0.25-2.25]$ & $1.34-0 i$ \\
\hline & 35 & $0.57[0.05-1.95]$ & $1.34-0 i$ \\
\hline & 47 & $0.57[0.05-1.95]$ & $1.36-0 i$ \\
\hline & 88 & $0.50[0.05-1.65]$ & $1.36-0 i$ \\
\hline & 140 & $0.17[0.05-2.0]$ & $1.44-0 i$ \\
\hline
\end{tabular}

${ }^{a}$ Too nonspherical to fit.

${ }^{b}$ Only fair agreement due to asphericity, but best fit is indicated.

Although it is expected that a majority of marine aerosols can be approximated as ensembles of spheres, scattering that results from deviation from sphericity provides important information regarding the properties of nonspherical marine aerosols. If the particles have spherical symmetry, then the matrix element $S_{22}$ normalized by $S_{11}$ is unity. Deviation of $\mathbf{S}_{22}$ from unity has been observed for laboratory aerosols and marine particles. ${ }^{14,43-46}$
Quinby-Hunt et al. ${ }^{46}$ have shown that it is possible to use the measured values of $\mathbf{S}_{22}$ to quantify and separate the nonspherical contributions to scattering on $S_{11}$ and $\mathbf{S}_{12}$.

\section{Calculations and Model Verification}

Mie calculations ${ }^{46}$ were used for two purposes: to determine the size distributions and refractive indices of aerosols whose scattering properties were measured, and to predict the polarized scattering properties of a variety of aerosols that might be encountered in the marine environment. The Lawrence Berkely National Laboratory (LBNL) model predicts the polarization properties of light scattered from combinations of multiple components of Gaussian and log normal distributions of spheres and coated spheres. The model was verified by use of measurements of scattering from water aerosols generated in the laboratory (see below for experimental details). Size distributions and refractive indices of particles contributing to an experimentally determined Mueller matrix cannot be determined directly. The process is iterative. We start with likely size distributions and refractive indices for the particles, calculate the scattering they would contribute and compare that with the observed scattering properties of the aerosol. Depending on the results of the comparison, input parameters are adjusted until the agreement between calculated and observed scattering is optimized. The sensitivity and uncertainty of the solution to the inverse problem depend on the degree of sphericity of the aerosol and its median size.
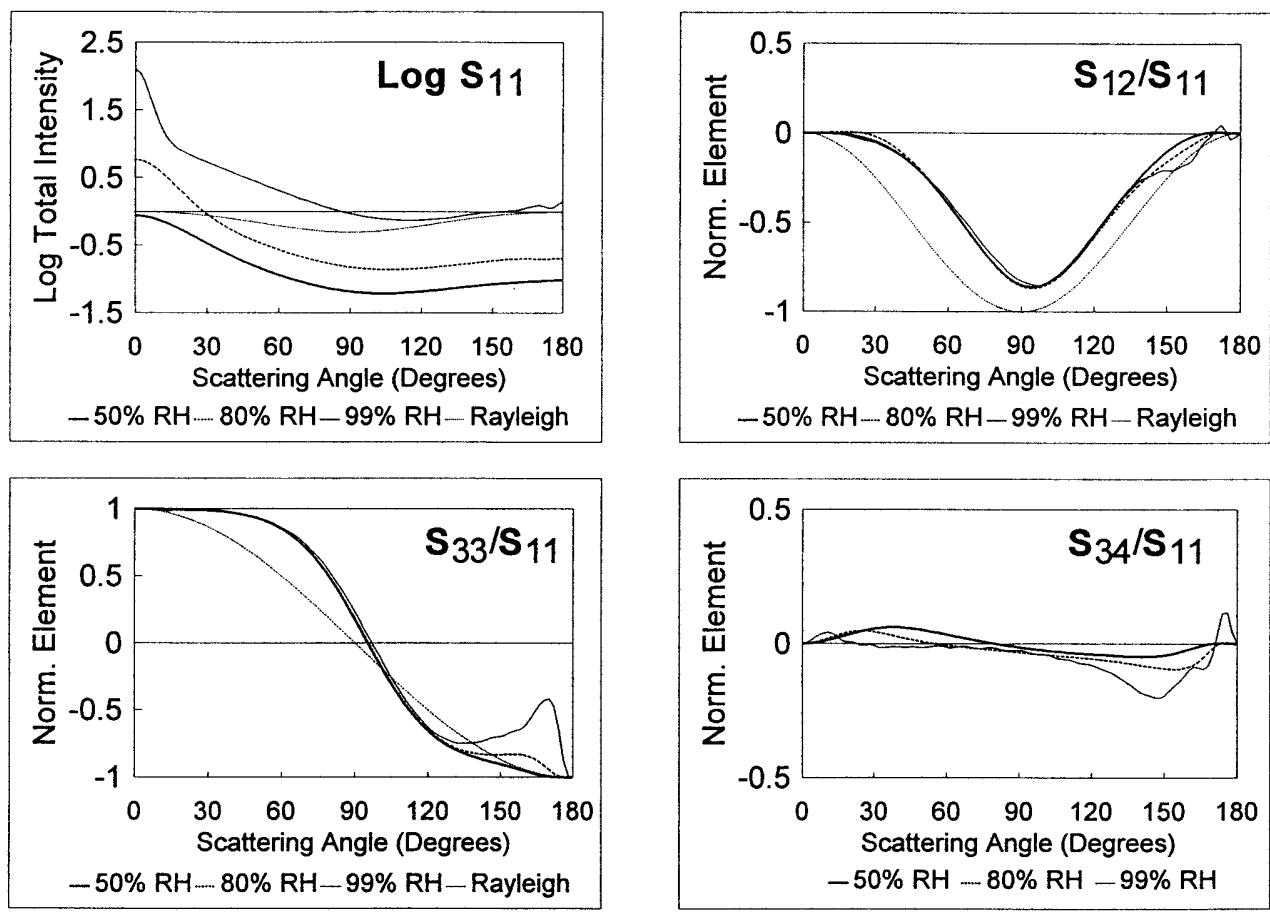

Fig. 4. Comparison of scattering predicted for a marine aerosol as described in the AFGL model ${ }^{25}$ at various humidities with scattering calculated with the Rayleigh approximation. Details of the AFGL are described in the text and Table 1. Note that $\mathbf{S}_{34}$ is zero in the Rayleigh approximation. 

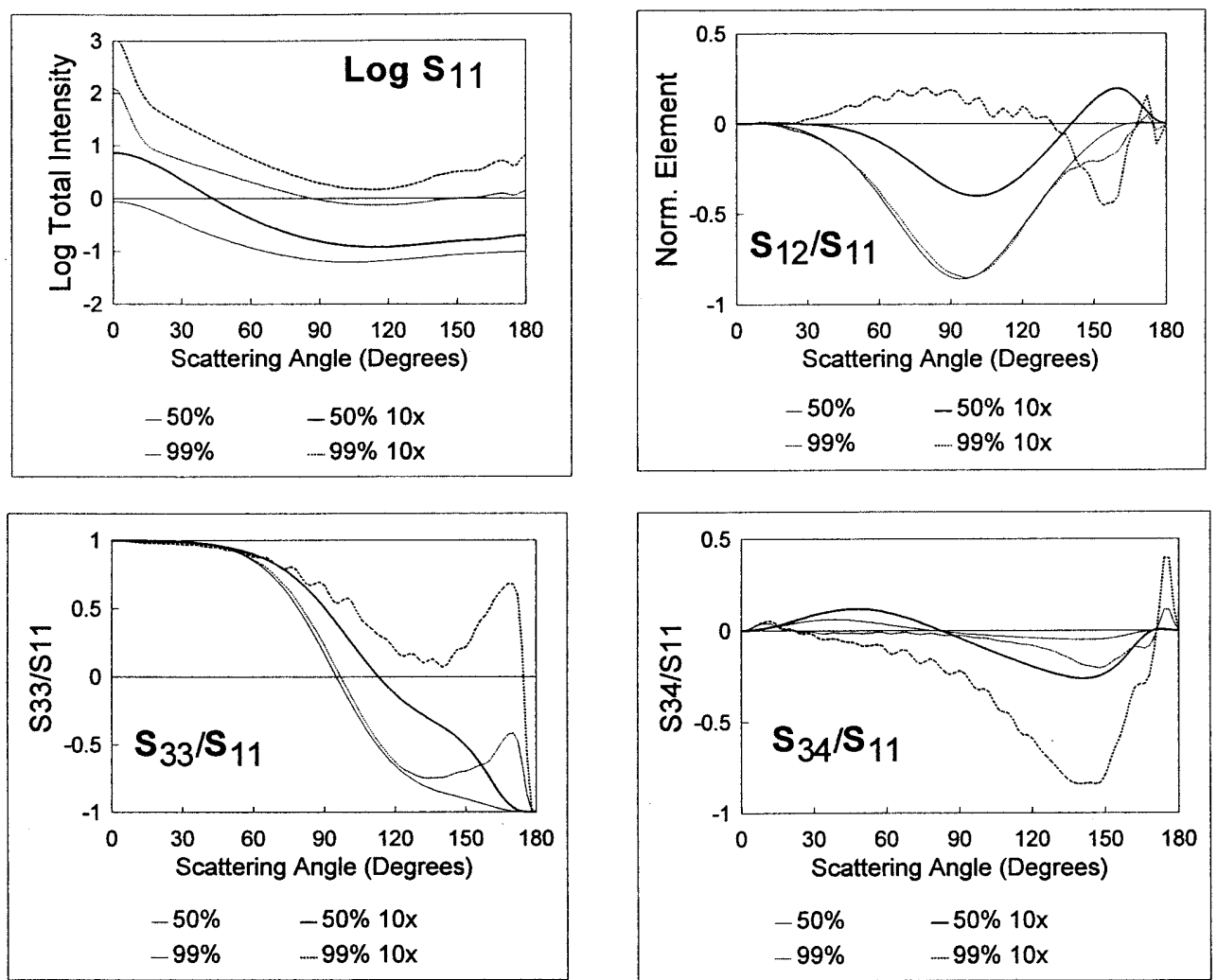

Fig. 5. Comparison of the scattering predicted by the AFGL marine aerosol at $50 \%$ and $99 \% \mathrm{RH}$ with aerosols in which the sea-salt number distribution is increased tenfold.

For spherical aerosols whose median radius is the greater than the wavelength of light, the refractive index can be optimized to within \pm 0.005 . The median radius of the ensemble can be optimized to within $\pm 0.25 \mu \mathrm{m}$, as can the range of the distribution. For example, for the solution shown in Fig. 2, the refractive index is $1.33 \pm 0.002$; the size distribution is described as median radius, $1.75 \mu \mathrm{m}( \pm 0.15 \mu \mathrm{m})$, and modal radius, $1.00 \mu \mathrm{m}$. The range of the distribution is $0.75 \mu \mathrm{m} \pm 0.15 \mu \mathrm{m}$ to $2.75 \mu \mathrm{m} \pm 0.15 \mu \mathrm{m}$.

Figure 2 shows the angle dependence of the 16element Mueller matrix for the pure water aerosol compared with calculations. Note that, as expected, the off-diagonal block elements are zero; $\mathbf{S}_{22}$ is unity; $\mathbf{S}_{12}=\mathbf{S}_{21}, \mathbf{S}_{33}=\mathbf{S}_{44}$, and $\mathbf{S}_{34}=-\mathbf{S}_{43}$. Results of calculations for scattering from hydrated $\mathrm{NaCl}$ and ammonium sulfate were in excellent agreement with the experimental results of Perry et al. ${ }^{14}$ and unpublished results ${ }^{47}$ (courtesy of D. Huffman) for $\left(\mathrm{NH}_{4}\right)_{2} \mathrm{SO}_{4}$ and $\mathrm{NaCl}$ at both 325 and $633 \mathrm{~nm}$, as well as ours presented here. Results of measurements were checked for consistency by use of the theoretical inequalities derived by Fry and Kattawar. ${ }^{48,49}$

\section{Experimental Procedure}

Characterizing marine aerosols and measuring their optical properties in the field present a number of problems. Natural aerosols are complex mixtures; collection is difficult and by its nature alters the natural state of the aerosol. Collection of aqueous aero- sols is particularly problematic. Measurement of the polarization properties of scattered light in situ is difficult because of the low signal and lack of controlled conditions. Such measurements can be made by bistatic nephelometry, ${ }^{50,51}$ but the technique is still under development. Studying laboratorygenerated aerosols allows us to use an angle-scanning nephelometer and to control the homogeneity, concentration, flow, and stability of the aerosol under examination. Salt-containing water aerosols were generated by the nebulizer-desiccation system.

\section{A. Scanning Polarization-Modulated Nephelometer}

In the angle-scanning polarization-modulated nephelometer (described in detail in Refs. 52 and 53; shown in Fig. 3a), a 532-nm cw laser passes through a linear polarizer and through a photoelastic modulator, then to the sample region. Light passes through phase retarders and linear polarizers to a photomultiplier tube, mounted on the rotating arm, that measures the scattered light. By varying the modulator angle and choice of filters and retarders, all 16 elements of the Mueller matrix were measured from $11^{\circ}$ to $170^{\circ}$. To check for instrumental consistency, two sets of data were collected at different times with different combinations of polarizers and retarders for 9 of the 16 Mueller matrix elements. As Figure 2 shows, agreement from one measurement to the next is excellent. Any differences ob- 

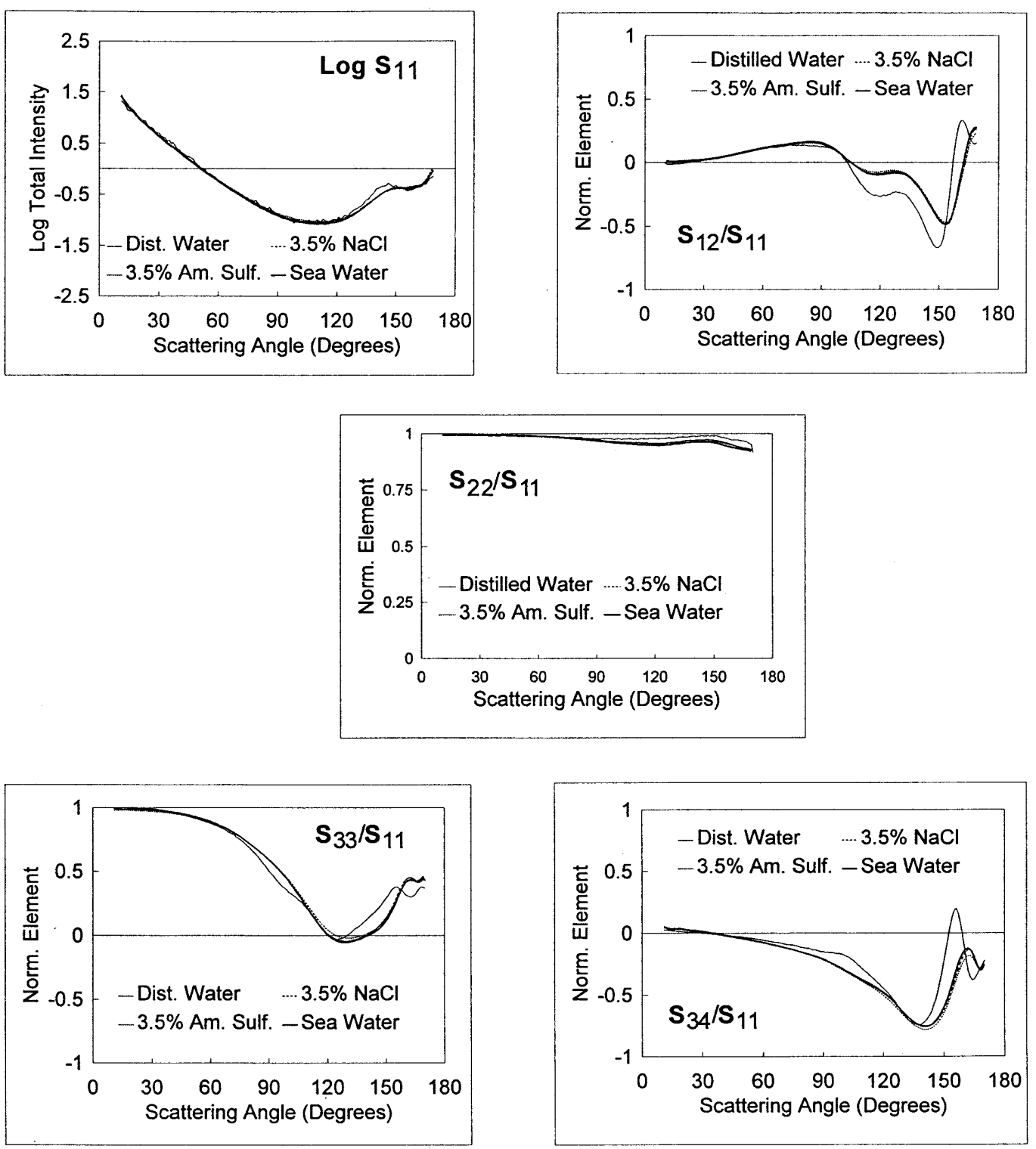

Fig. 6. Experimental Mueller scattering matrix elements for four room-temperature aerosols: distilled water, seawater, a $3.5 \% \mathrm{NaCl}$ solution, and a 3.5\% $\left(\mathrm{NH}_{4}\right)_{2} \mathrm{SO}_{4}$ solution. The scattering observed for all three salt aerosols is nearly the same within experimental error. The difference observed in the distilled water aerosol scattering can be attributed to the presence of somewhat larger particles in the aerosol.

served seem to be more of a function of polarizer alignment than of changes in aerosol characteristics.

\section{B. Nebulizer-Desiccation System}

The nebulizer-desiccation system, shown in Fig. 3b and based on that developed by Hunt ${ }^{52}$ and Hunt and Huffman $^{53}$ can be divided into three main parts: production, desiccation, and delivery.

The production system is composed of an ultrasonic nebulizer (a commercial humidifier) and a settling chamber. Water in the humidifier is ultrasonicated to produce an aerosol. Air from the humidifier, supplemented by laboratory air as needed, carries the aerosol particles to the settling chamber. Flow from the settling chamber is regulated with a release valve. The settling chamber was necessary to even the flow from the nebulizer and to remove larger droplets.

The aerosol is desiccated by being passed through a tube wrapped in heating tape and an optional Drierite-lined tube. Aerosols flow from the settling chamber into the heating tube. One thermocouple measures the temperature of the heating tape. Another thermocouple, in the middle of the aerosol flow at the center of the heating tube, measures the temperature in the middle of the aerosol. Depending on the temperature of the heating tube, differing amounts of water are evaporated from the aerosol and absorbed by the Drierite. Although aerosols were heated to as high as $180{ }^{\circ} \mathrm{C}$, it was not possible to dry them completely.

Wide tubing delivers the aerosol flow to a focusing 

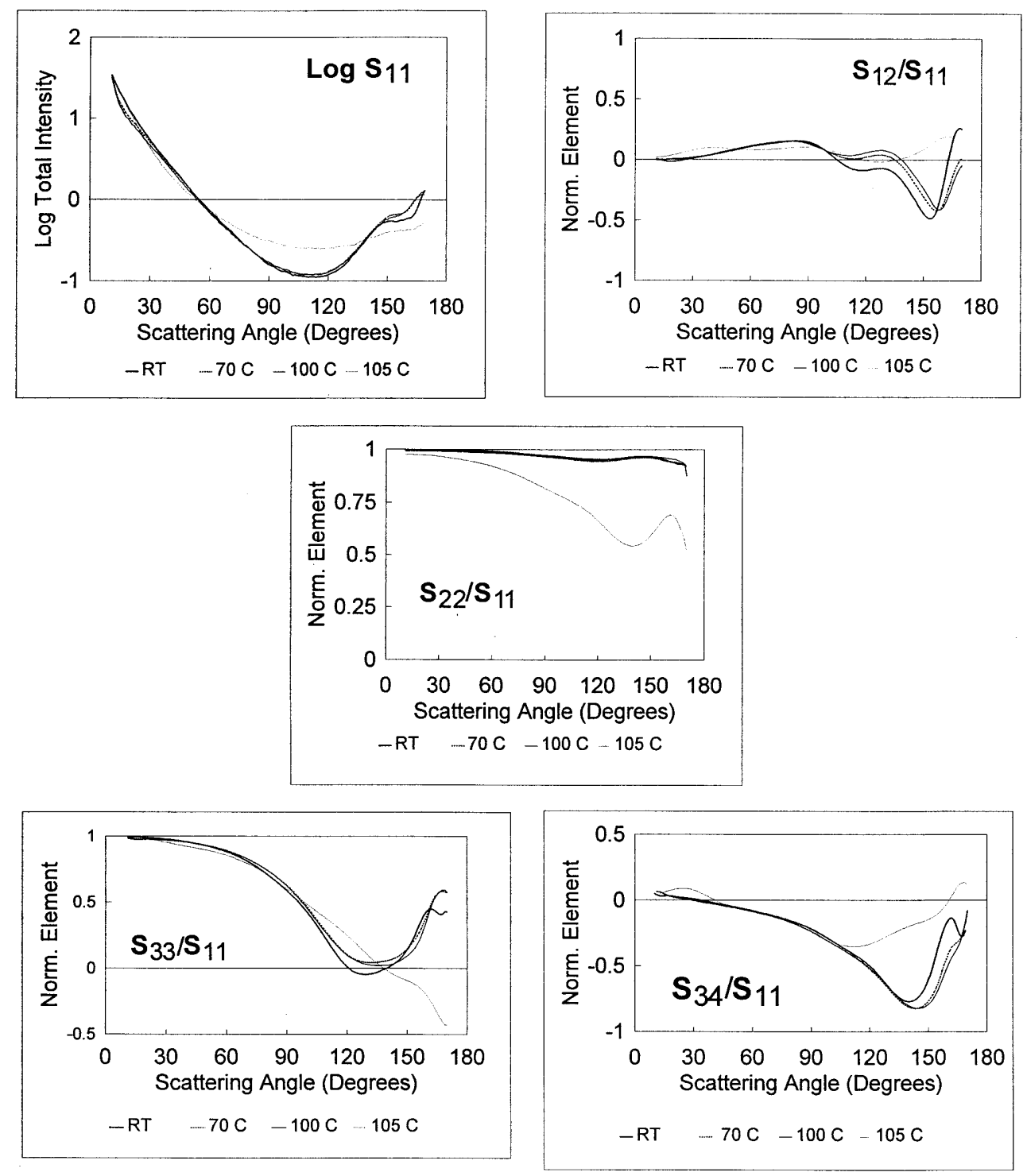

Fig. 7. Experimental Mueller scattering matrix elements, $S_{11}, \mathbf{S}_{12}, \mathbf{S}_{22}, \mathbf{S}_{33}$, and $\mathbf{S}_{34}$, for $\mathrm{NaCl}$ at room temperature, $70^{\circ}, 100^{\circ}$, and $105^{\circ} \mathrm{C}$.

attachment in the nephelometer, which directs the aerosol as a uniform stream to the sample region. After measurement, the aerosol is removed from the nephelometer with a low-pressure orifice. The focusing attachment permits a more uniform and directed flow than the larger tubing. The attachment also provides a sufficiently small sample region such that scattering volume corrections of the total intensity are not required for comparison with computations.

\section{Measurements}

Scattering from pure water aerosols was measured for a variety of purposes. Initially, measurements were used to determine the stability and reproducibility of the nebulizer-desiccation system. Comparisons between measurement and LBNL model results demonstrated that the models could be used to describe the scattering from these aerosols (Fig. 2). Water aerosols were used to simulate marine fogs and hazes. Calculations used the refractive index of pure water (1.335 - 0i, Ref. 54) and appropriate size distributions.

Polarized light scattering was measured from aerosols of solutions of $\mathrm{NaCl},\left(\mathrm{NH}_{4}\right)_{2} \mathrm{SO}_{4}$, and seawater. These measurements were all used to investigate scattering from sea-salt aerosols as a function of dehydration. Initially, light scattering was measured from aerosols generated with a 35\%o solution of $\mathrm{NaCl}$ (the concentration is roughly that of seawater). As $\mathrm{NaCl}$ aerosols approach dryness, the resultant particles deviate from sphericity. When the particles become nonspherical, it is not possible to confirm the size and refractive index (and therefore the humidity) from Mie calculations. Therefore additional measurements were made of light scattering from $\left(\mathrm{NH}_{4}\right)_{2} \mathrm{SO}_{4}$ aerosols, because, previously, dry $\left(\mathrm{NH}_{4}\right)_{2} \mathrm{SO}_{4}$ aerosols have been observed to be nearly spherical. ${ }^{14,27}$ Because $\left(\mathrm{NH}_{4}\right)_{2} \mathrm{SO}_{4}$ particles are thought to remain spherical as they approach dryness, measurements of their scattering 

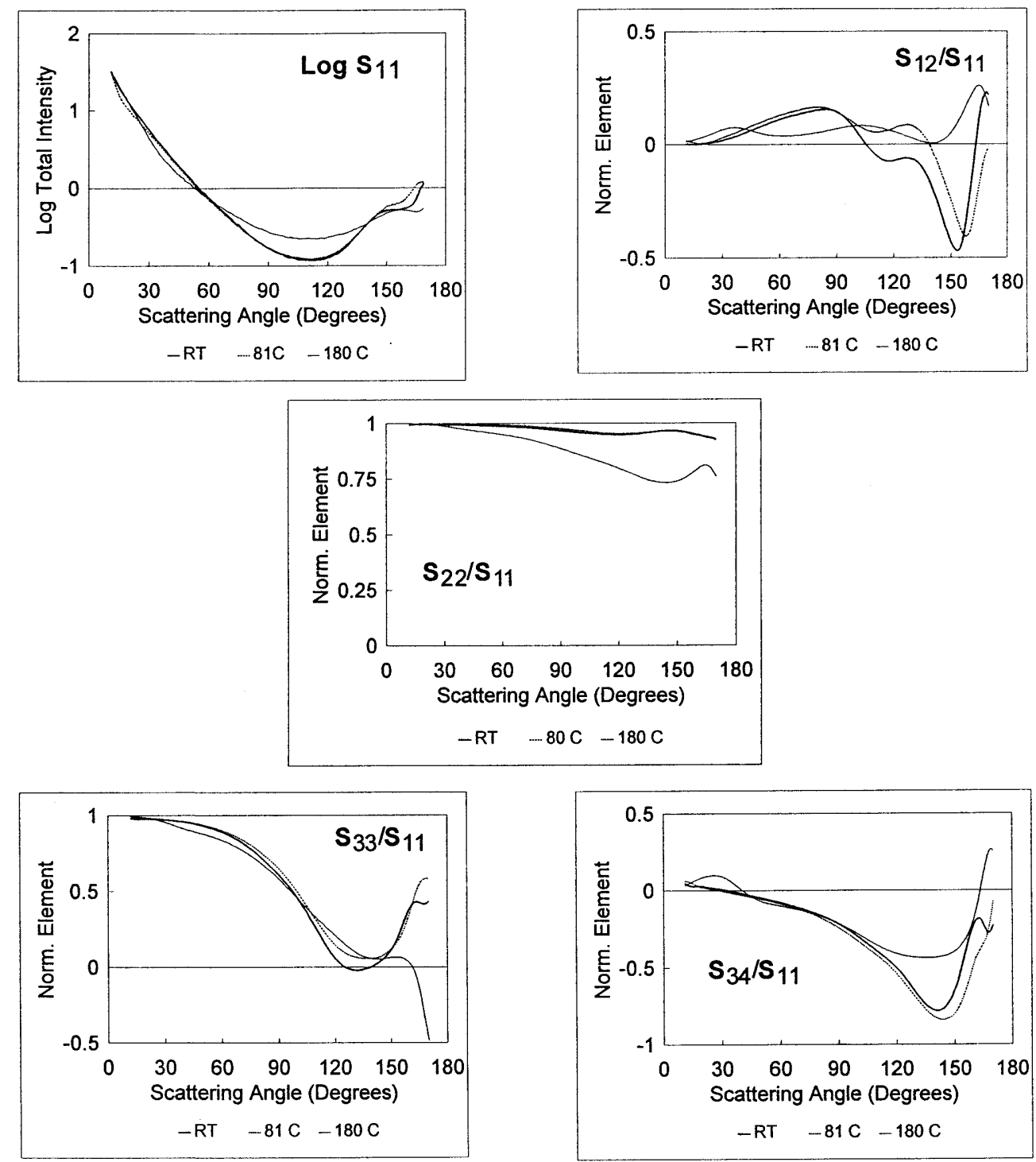

Fig. 8. Experimental Mueller scattering matrix elements, $S_{11}, \mathbf{S}_{12}, \mathbf{S}_{22}, \mathbf{S}_{33}$, and $\mathbf{S}_{34}$, for $\left(\mathrm{NH}_{4}\right)_{2} \mathrm{SO}_{4}$ at room temperature, $80^{\circ}$ and $180{ }^{\circ} \mathrm{C}$.

as $\mathrm{RH}$ is decreased in the nebulizer-desiccation system would provide a measure of the efficacy of drying techniques. Finally, to explore the polarization properties of the seawater aerosols, light scattering measurements were made from aerosols nebulized from seawater collected near shore at Fort Cronkite, California (salinity $\sim 32.5 \%$ ). The composition and experimental conditions for the measurements are given in the first two columns of Table 2.

Mie calculations were used to determine the size distribution and the refractive index for the aerosols. If the particles were spherical, agreement between observation and calculation was excellent. Figure 2 shows typical agreement. As noted above, it is only necessary to calculate four elements of the scattering matrix for spherical particles; all others are zero, equal to, or the negative of the four calculated; $\mathbf{S}_{22}$ is unity. The particles were considered to be nonspherical when $\mathbf{S}_{22}$ deviated significantly from unity.
When $\mathbf{S}_{22}$ is less than 0.9 , agreement between observation and calculation is necessarily poor.

\section{Results and Discussion}

A. Models of the Component with $r_{\text {mode }} \sim 0.03 \mu \mathrm{m}$

An initial question was the veracity of modeling the smaller particles $\left(r_{\text {mode }} \sim 0.03 \mu \mathrm{m}\right)$ as solid spheres. Presumably, for the water-soluble component, the approximation is valid. However, small-fraction particles are not necessarily soluble, and therefore several other models may be appropriate. The particle may form a core with a shell of seawater; the particle may remain undissolved; or the small component may be well described by the $30 \% / 70 \%$ insoluble/soluble approximation of Shettle and Fenn. ${ }^{25}$ Calculations show that all the above descriptions are indistinguishable given current instrumentation. $\mathbf{S}_{12}$, and $\mathbf{S}_{33}$ for all these models are well described by 

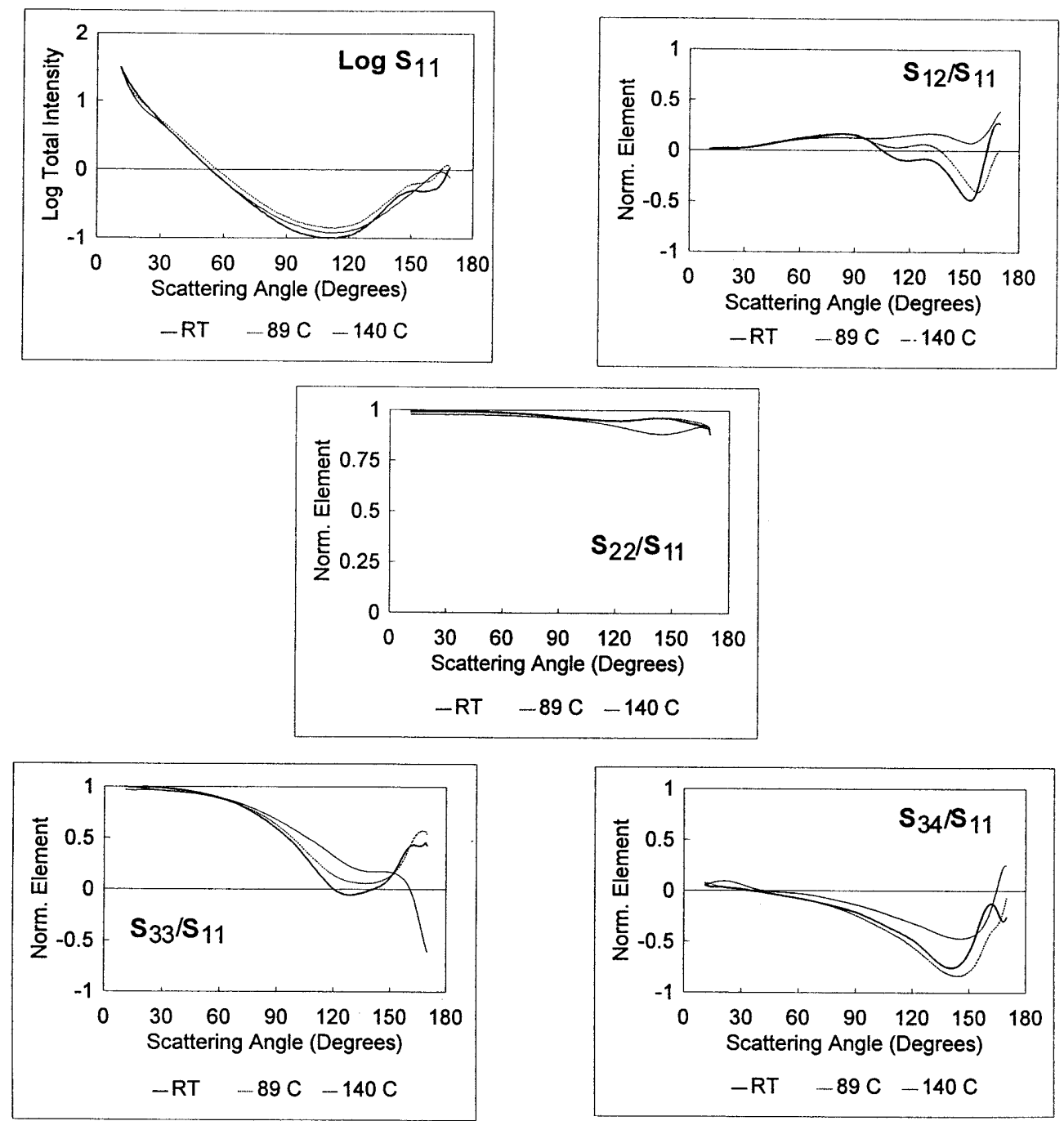

Fig. 9. Experimental Mueller scattering matrix elements, $S_{11}, \mathbf{S}_{12}, \mathbf{S}_{22}, \mathbf{S}_{33}$, and $\mathbf{S}_{34}$, for seawater at room temperature, $90^{\circ}$ and $140{ }^{\circ} \mathrm{C}$.

the Rayleigh approximation. $S_{11}$ and $\mathbf{S}_{34}$ show some deviation from Rayleigh scattering even though the particles are $1 / 20$ th the wavelength of light. $\mathbf{S}_{34}$ deviates from zero; and the results of the various approximations vary, but in all cases its value is less than $1 \%$.

\section{B. Variation with Humidity}

To investigate variation in the Mueller matrices with changing humidity for typical MABL aerosols, we calculated scattering assuming the size distributions and refractive indices in the AFGL model. ${ }^{25}$ Scattering for a typical marine aerosol was calculated with the data in Table 1 at 50\%, 80\%, and 99\% RH. The results are displayed in Fig. 4. The predicted scattering is dominated by the smallest component of the aerosol, which is not unexpected given their predominance in the model. Their scattering differs significantly from Rayleigh scattering (note particularly the deviation of $\mathbf{S}_{34}$ from zero). The minimum in $\mathbf{S}_{12}$, the linear polarization, is $\sim 80 \%$, significantly less polarization than the $100 \%$ predicted for Ray- leigh scatterers. As Fig. 4 shows, varying the humidity has only a small effect on the aerosol polarization properties predicted by the AFGL model. The absolute value of $S_{11}$, the phase function, increases with size, and as the size increases, the intensity of forward scattering increases.

If the relative number of sea-salt particles is increased relative to the fine fractions to simulate a Junge distribution, the effect of humidity becomes more pronounced. Figure 5 compares the scattering expected for the AFGL marine aerosol model ${ }^{25}$ at $50 \%$ and $99 \% \mathrm{RH}$ with that predicted when the sea-salt component is increased tenfold. This increase in numbers of sea-salt particles in the lower MABL could result from increased wind and wave action. The changes are considerable. At 50\% humidity with a higher concentration of salt particles, the linear polarization, which at the lower concentration was pronounced $(\sim 80 \%)$ and negative, diminishes considerably to $\sim 40 \%$. $\quad \mathbf{S}_{12}$ changes from positive to negative at roughly $150^{\circ}$, indicating a change from horizontal to vertical polarization. At 99\% humidity 
the angular distribution of linear polarization was very much like the linear polarization predicted for $50 \%$ humidity when the initial concentration of the SSC component was that suggested by the AFGL model. However, at the higher concentration of particles the linear polarization is very small and slightly positive until $150^{\circ}$, at which time the sign changes. As Figure 5 shows, this is the reverse of the angular polarization predicted at $50 \%$ humidity. Similar dramatic changes can be seen in $\mathbf{S}_{33}$ and $\mathbf{S}_{34}$.

\section{Aerosol Laboratory Scattering Measurements}

Comparison of the measured scattering from all the aerosols generated at room temperature demonstrates that at high $\mathrm{RH}$ they are reasonably described as collections of spheres. This point is demonstrated in Fig. 6, which shows that $\mathbf{S}_{22}$ is $\sim 1$ for all four aerosols at room temperature. The size distributions determined for the aerosols (Table 2) indicate that the sizes being generated by the nebulizer are well within the range used in the AFGL model ${ }^{25}$ for the maritime (larger) component.

The modal radii $\left(r_{\text {mode }}\right)$ determined by fitting of the experimental data with Mie calculations (not shown) indicated that the saline aerosols are somewhat smaller than that determined for the distilled water (see Table 2). Possibly the ionic strength of the solute has reduced the surface tension of the solution sufficiently to affect the size of the particles produced by the nebulizer. The polarization properties of the three saline aerosols are similar. Scattering such as is observed here would probably be observed for the SSC component in high-humidity situations.

As the temperature is increased in the desiccator unit, the polarization properties of the aerosols change (Figs. 7-9). At $105{ }^{\circ} \mathrm{C}$, the $\mathrm{NaCl}$ aerosol deviated so far from sphericity as to make rigorous curve fitting inappropriate (Fig. 7). The observed minimum in $\mathbf{S}_{22}$ was 0.54 . Figure 7 shows that as the temperature is increased there are subtle changes in the polarization properties as the $\mathrm{RH}$ changes and the particles decrease in size. When the particles in the aerosol become nonspherical, the polarization properties change significantly and in a manner not predicted by Mie calculations.

As the temperature was increased, $\left(\mathrm{NH}_{4}\right)_{2} \mathrm{SO}_{4}$ remained spherical until a very high temperature was reached $-180^{\circ} \mathrm{C}$. The size distribution and refractive index could be approximately fitted with Mie calculations for a modal radius of $0.23 \mu \mathrm{m}$ and a refractive index of 1.48 (Fig. 8). This aerosol was not yet dry; the refractive index of dry $\left(\mathrm{NH}_{4}\right)_{2} \mathrm{SO}_{4}$ is $\sim 1.53$ at $532 \mathrm{~nm}$. Nonetheless, $\mathbf{S}_{22}$ deviates significantly from unity. Perry et al. ${ }^{14}$ observed spherical particles even at dryness. The discrepancy may be due to differing salt concentrations, temperature or humidity conditions, or to the nebulizer configuration.

As the temperature was increased, the seawater aerosol deviated from sphericity when the $r_{\text {mode }}$ was $0.2 \mu \mathrm{m}$ and its refractive index was 1.44 (Fig. 9). At the small sizes observed here, representing low levels
Table 3. Various Descriptions of Soot Used for Investigating the Effect of Varying Refractive Indices and Distributions on Scattering

in the $\mathrm{MABL}^{a}$

\begin{tabular}{clllll}
\hline \multicolumn{1}{c}{ Model } & $\begin{array}{l}r_{\text {mode }} \\
(\mu \mathrm{m})\end{array}$ & $\begin{array}{l}r_{\text {min }} \\
(\mu \mathrm{m})\end{array}$ & $\begin{array}{l}r_{\text {max }} \\
(\mu \mathrm{m})\end{array}$ & $\sigma$ & $m$ at $\sim 500$ \\
\hline AFGL & & & & & \\
$\quad$ Small component & 0.025 & 0.0035 & 0.2 & 0.35 & $1.75-0.45 i$ \\
Large component $^{2}$ & 0.43 & 0.04 & 3.5 & 0.4 & $1.75-0.45 i$ \\
Soot $^{b}$ & 0.025 & 0.0035 & 0.2 & 0.35 & $2.29-0.87 i$ \\
Soot $^{c}$ & 0.43 & 0.04 & 3.5 & 0.4 & $2.29-0.87 i$ \\
& 0.025 & 0.0035 & 0.2 & 0.35 & $1.7-0.8 i$ \\
Soot $^{d}$ & 0.43 & 0.04 & 3.5 & 0.4 & $1.7-0.8 i$ \\
& 0.025 & 0.0035 & 0.2 & 0.35 & $1.334-0.12 i$ \\
Soot $^{e}$ & 0.43 & 0.04 & 3.5 & 0.4 & $1.334-0.12 i$ \\
& 0.2 & 0.005 & 10 & 1.35 & $1.75-0.45 i$
\end{tabular}

${ }^{a}$ For the first four models the reference refers to the refractive index; the number distribution is based on the AFGL model. For the Kuwaiti soot the distribution was from the literature, and the refractive index was from Ref. 25.

${ }^{b}$ Ref. 56.

${ }^{c}$ Ref. 57.

${ }^{d}$ Ref. 58.

${ }^{e}$ Ref. 59 .

of humidity, the linear polarization is positive for this component and close to zero. The seawater aerosol remained spherical until much smaller sizes than did the $\mathrm{NaCl}$ or $\left(\mathrm{NH}_{4}\right)_{2} \mathrm{SO}_{4}$ aerosols. This is plausible. Although $\mathrm{NaCl}$ is the dominant component of seawater, it is not necessarily the first to precipitate; generally, in the formation of evaporites, carbonates and sulfates precipitate first, followed by the chlorides. ${ }^{55}$ Thus, considering our experimental conditions, it would seem that under most conditions the scattering from SSC particles would be well described by Mie calculations. However, Mészáros and Vissy ${ }^{26}$ found evidence of differential crystallization in collected dry seawater particles. If this occurs in situ, then observed polarization properties would display polarization properties not predicted by Mie calculations.

\section{Effect of Soot on Scattering in the Marine Atmospheric Boundary Layer}

To explore the presence of a widely occurring and highly absorptive component in the MABL, scattering from carbon soot was calculated. In coastal areas and near shipping lanes soot can be an important component of marine aerosols. This component tends to have an important effect on the scattering because the real and the imaginary parts of the refractive index are large. To further complicate matters, the values for the refractive index vary considerably with the source of data, which may indicate real variation among soots depending on their source. This is probably due to nonfully dense agglomerations of carbon particles or the presence of homogeneous low-absorptive to nonabsorptive products in the aerosol. Sampling and quantifying the amounts and density of carbon present presents difficulties. Table 3 summarizes some of the data available from particle measurements and pure car- 

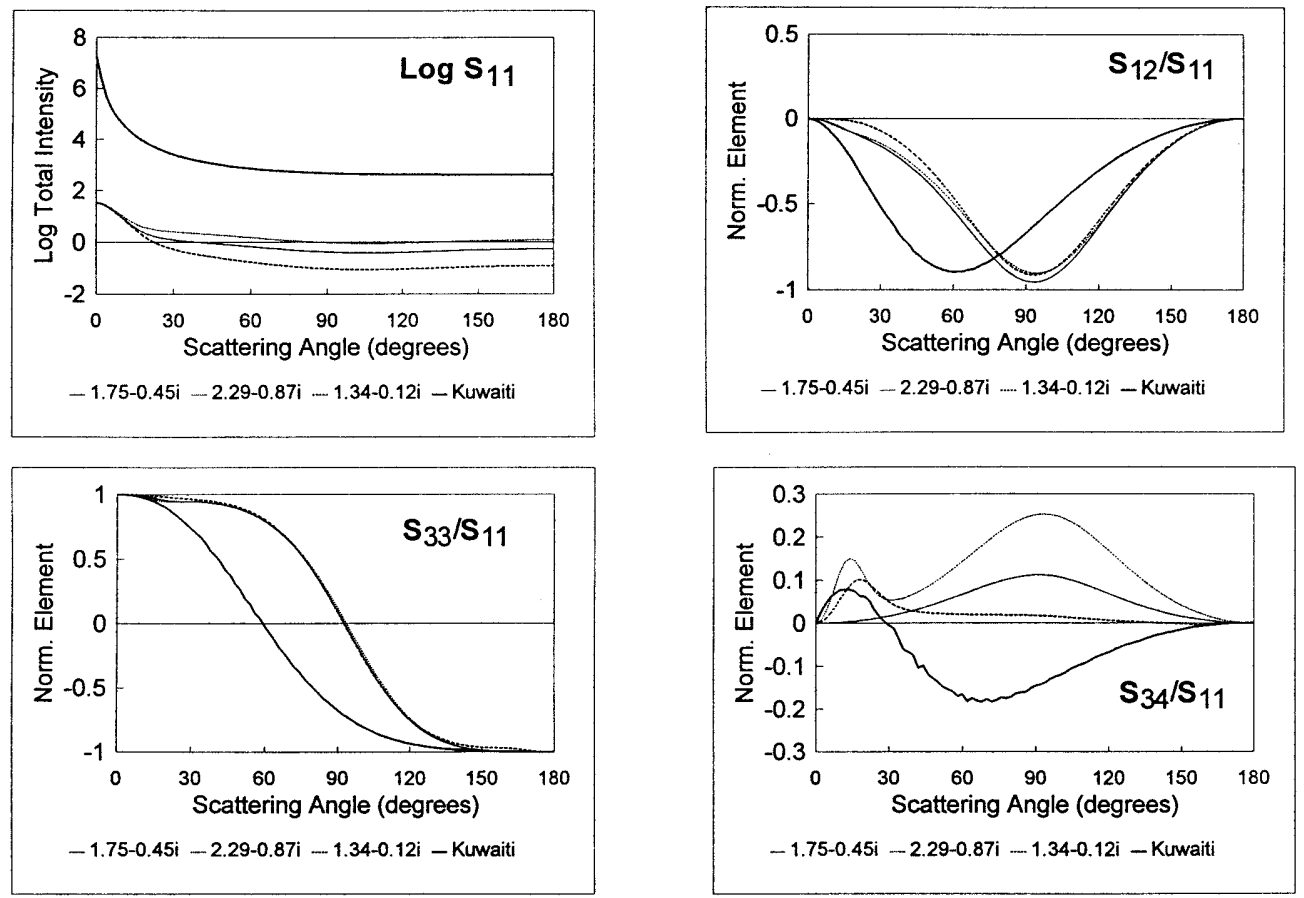

Fig. 10. Mueller scattering matrix elements, $S_{11}, \mathbf{S}_{12}, \mathbf{S}_{33}$, and $\mathbf{S}_{34}$, calculated for soots having a range of complex refractive indices and size distributions as described in Table 3.

bon. Diesel combustion products tend to be in the size range of the small component of the AFGL ${ }^{25}$ values. The refractive indices of pure amorphous carbon are closest to those given by Arakawa et al. ${ }^{56}$

The first four models listed in Table 3 varied only in the refractive index (the ratio of small to large component was 0.999875 to 0.000125 ). The AFGL refractive index is a composite of a number of observations; that of Arakawa et al. ${ }^{56}$ is from arc evaporated carbon films; Pluchino et al. ${ }^{56}$ measured single, spherical carbon particles; and Batten ${ }^{58}$ measured soot from kerosene. Other results report refractive indices varying from $1.56-0.47 i$ to $2.0-$ 01.0i.60-62 The last soot description is a model based on the size distribution observed by Parungo et $a l .59$ of the soots derived from the oil fires in Kuwait. Observations at various distances from Kuwait were taken at $1-6 \mathrm{~km}$ in altitude, considerably above the MABL, but of practical interest as they were collected in the field. Parungo et al. ${ }^{59}$ report a broad distribution of particle sizes that were approximated here as a broad log normal distribution adjusted roughly to fit the number distribution reported, which was at $3.7 \mathrm{~km}$ in altitude and $160 \mathrm{~km}$ from Kuwait.

The results of scattering calculations for the various soots in Table 3 are given in Fig. 10. When only the refractive index changes, the form of the scattering is generally unchanged. When the size distribution is significantly different, that is, for the Kuwaiti soot, the predicted scattering changes. The linear polarization as seen in $\mathbf{S}_{12}$ is slightly reduced, and the maximum depolarization occurs at $60^{\circ} . \quad \mathbf{S}_{34}$ for the Kuwaiti soot changes sign at angles $>60^{\circ}$. The family of $\mathbf{S}_{34}$ curves demonstrates the range of polariza- tion that could be expected from just one component of marine aerosols.

One last comparison is of interest, that of the contribution to the polarization of scattering from soot and sea salt. This is of import, particularly in the coastal zone, because if the scattering due to the components differs, then the polarized light scattering could be expected to change depending on the dominant component. To make this comparison, the scattering calculated on the basis of the physical description of the maritime component of the AFGL model ${ }^{25}$ at $80 \% \mathrm{RH}$ was compared with the scattering predicted by use of the AFGL physical description for the large soot component. The size distribution for the soot component was that for $0 \%$ $\mathrm{RH}$, because soot is not particularly soluble. These two hypothetical components were compared with the polarization measured for a seawater aerosol, the aerosol at $47^{\circ} \mathrm{C}$, which most closely approximated the model parameters for marine aerosol at $80 \%$ humidity. The angular distributions of the total intensities $\left(S_{11}\right)$ of these components do not differ significantly, but the polarizations do differ significantly (Fig. 11). The implications with respect to the linear polarization are dramatic. As noted above, the scattering predicted for the sea salt (both the measured and modeled curves) is largely horizontal (positive), and not particularly intense, becoming vertical (negative) in the backscatter direction. The soot, on the other hand, is primarily vertically polarized, particularly near $60^{\circ}$. Similarly, the contributions of soot and salt differ significantly in $\mathbf{S}_{33}$ and $\mathbf{S}_{34}$. Thus these dif- 

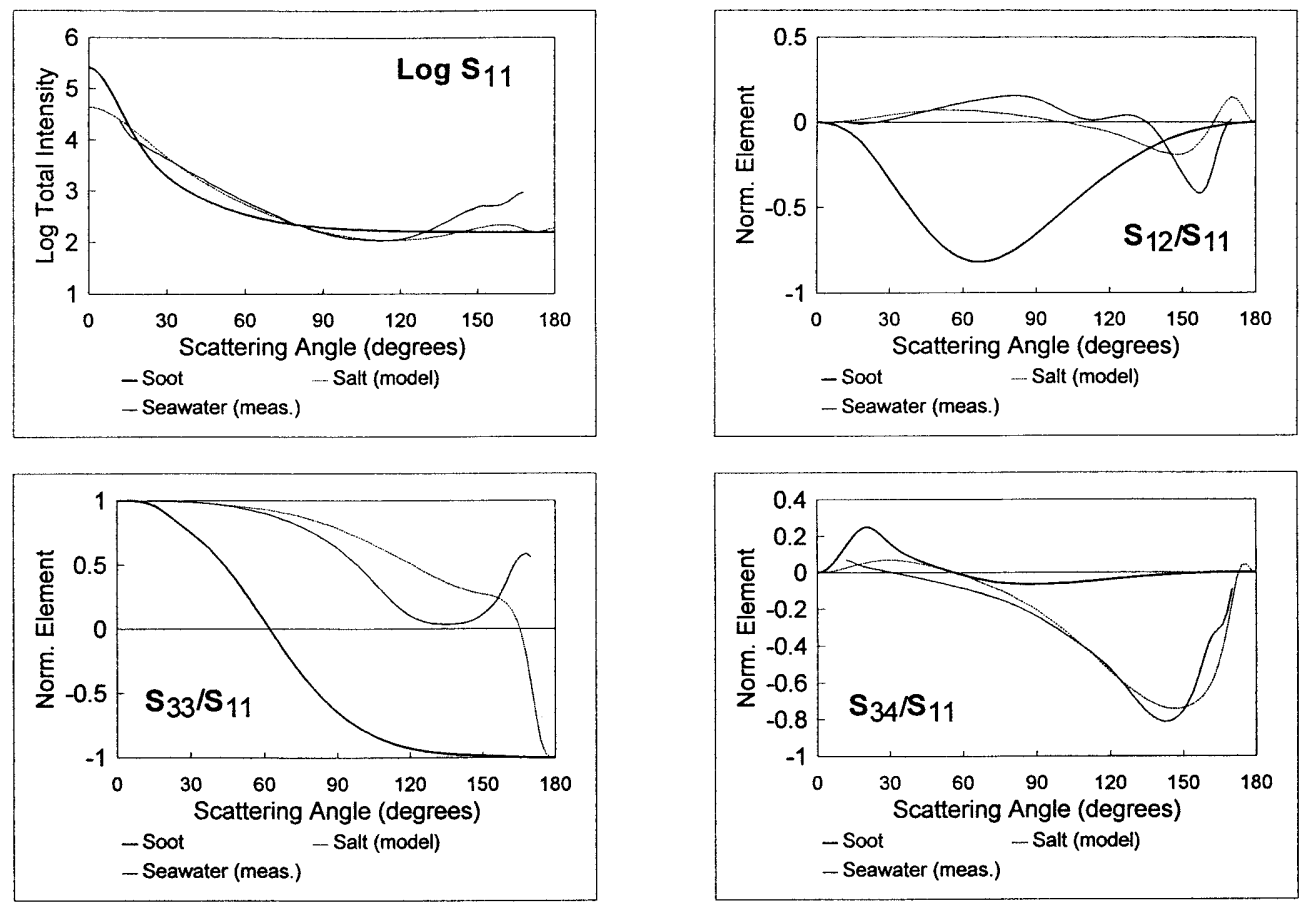

Fig. 11. Mueller scattering matrix elements, $S_{11}, \mathbf{S}_{12}, \mathbf{S}_{33}$, and $\mathbf{S}_{34}$, calculated for soot $\left(r_{\text {mode }}=0.55 \mu \mathrm{m}, n=1.75-0.45 i\right.$, log normal, $\sigma=0.4]$ and sea salt $\left(r_{\text {mode }}=0.35 \mu \mathrm{m}, n=1.355-0.45 i, \log\right.$ normal, $\sigma=0.4$ ) compared with the polarized scattering measured for a seawater aerosol at $47^{\circ} \mathrm{C}$, having $r_{\text {mode }}$ approximately $0.57 \mu \mathrm{m}$ and $n=1.36-0 i$.

ferences may be exploited to improve visibility with polarizing optics.

\section{Conclusions}

In this paper we have demonstrated that the agreement between laboratory measurements and Mie calculations has established the validity of studying MABL hazes with these tools. Therefore, within the limits of the validity of the assumptions regarding the physical properties of the aerosols, this approach can be used to predict the scattering and polarization properties of marine hazes.

Calculations and measurements on laboratory aerosols indicate that scattering of visible light by aerosols in the MABL is distinctly not Rayleigh-like. The polarization properties of light scattered in the MABL vary with size, refractive index, and number distributions of particles. The results are sensitive to the details of the size and number distributions and therefore may be used to discriminate between aerosols. The size, number density, real and imaginary indices of refraction, and particle shape all have significant effects on the polarization characteristics of the scattered light and potentially on visibility, radiant transfer, and global albedo.

Examination of the figures presented in this paper can suggest that polarimetric techniques should be useful for improving visibility and imaging in the MABL. These should be exploited. However, the composition of aerosols in the MABL can be highly variable, particularly in the coastal zone. Because the number of measurements of the polarization of scattered light in the atmosphere is small, and in the coastal zone is virtually none, it is recommended that an in situ measurement program at representative sites be conducted to better characterize the scattering and polarization properties and variability of coastal marine hazes. Such a program in conjunction with appropriate theoretical considerations could further expedite and enhance development of techniques for improving visibility and remote imaging for various aerosol types, Sun angles, and viewing conditions.

We wish to thank Steve Ackleson for his support and interest in this research. This work was supported by the Office of Naval Research under contract N00014-94-F0043 through the U.S. Department of Energy under contract DE-AC03-765f00098. L. L. Erskine also wishes to thank the California Institute of Technology for partial support from a Summer Undergraduate Research Fellowship.

\section{References}

1. G. N. Plass, T. J. Humphreys, and G. W. Kattawar, "Oceanatmosphere interface: its influence on radiation," Appl. Opt. 20, 917-930 (1981).

2. G. W. Kattawar and C. N. Adams, "Stokes vector calculations of the submarine light field in an atmosphere-ocean with scattering according to a Rayleigh phase matrix: effect of interface refractive index on radiance and polarization," Limnol. Oceanogr. 34, 1453-1472 (1989).

3. H. B. Hallock and J. Hallajian, "Polarization imaging and mapping," Appl. Opt. 22, 964-966 (1983).

4. R. O. Briggs and G. L. Hatchett, "Techniques for improving underwater visibility with video equipment," Ocean Sci. Ocean Eng. 1\&2, 1284-1308 (1965).

5. J. Cariou, B. Le Jeune, J. Lotrian, and Y. Guern, "Polarization 
effects of seawater and underwater targets," Appl. Opt. 29, 1689-1695 (1990).

6. J. E. Solomon, "Polarization mapping," Appl. Opt. 20, 15371544 (1981).

7. G. D. Gilbert and J. C. Pernicka, "Improvement of underwater visibility by reduction of backscatter with a circular polarization technique," in Underwater Photo-Optics Seminar Proceedings (SPIE, Santa Barbara, Calif., 1966).

8. L. E. Mertens, In-Water Photography (Wiley-Interscience, New York, 1970).

9. P. Koepke and M. Hess, "Scattering functions of tropospheric aerosols: the effects of nonspherical particles," Appl. Opt. 27, 2422-2430 (1988).

10. W. A. Hoppel, J. W. Fitzgerald, G. M. Frick, R. E. Larson, and E. J. Mack, "Aerosol size distributions and optical properties found in the marine boundary layer over the Atlantic Ocean," J. Geophys. Res. Atmos. 95D, 3659-3686 (1990).

11. J. W. Fitzgerald, "Marine aerosols-A review," Atmos. Environ. Part A 25, 533-545 (1991).

12. D. Diermendjian, Electromagnetic Scattering on Spherical Polydispersions (American Elsevier, New York, 1969).

13. M. S. Quinby-Hunt, P. G. Hull, and A. J. Hunt, "Predicting polarization properties of marine aerosols," in Ocean Optics XII, J. S. Jaffe, ed., Proc. SPIE 2258, 735-746 (1994).

14. R. J. Perry, A. J. Hunt, and D. R. Huffman, "Experimental determinations of Mueller scattering matrices for nonspherical particles," Appl. Opt. 17, 2700-2710 (1978).

15. M. Z. Hansen and W. H. Evans, "Polar nephelometer for atmospheric particulate studies," Appl. Opt. 19, 3389-3395 (1980).

16. C. E. Junge, "Our knowledge of the physico-chemistry of aerosols in the undisturbed marine environment," J. Geophys. Res. 77, 5183-5200 (1972).

17. C. E. Junge, E. Robinson, and F. L. Ludwig, "A study of aerosols in the Pacific air masses," J. Appl. Meteorol. 8, 340-347 (1969).

18. R. Chesselet, J. Morelli, and P. Buat-Menard, "Variations in ionic ratios between reference sea water and marine aerosols," J. Geophys. Res. 77, 5116-5131 (1972).

19. R. Chesselet, M. Fontugne, P. Buat-Ménard, U. Ezat, and C. E. Lambert, "The origin of particulate organic carbon in the marine atmosphere as indicated by its stable carbon isotopic composition," Geophys. Res. Lett. 8, 345-348 (1981).

20. O. B. Toon and J. B. Pollack, "A global average model of atmospheric aerosols for radiative transfer calculations," J. Appl. Meteorol. 15, 225-246 (1976).

21. J. L. Gras and G. P. Ayers, "Marine aerosol at southern midlatitudes," J. Geophys. Res. 88, 10,661-10,666 (1983).

22. T. S. Bates, J. A. Calhoun, and P. K. Quinn, "Variations in the methanesulfonate to sulfate molar ratio in submicrometer marine aerosol particles over the South Pacific Ocean," J. Geophys. Res. 97, 9859-9865 (1992).

23. T. Novakov and J. E. Penner, "The effect of anthropogenic sulfate aerosols on marine cloud droplet concentrations," Nature 365, 823-826 (1992).

24. D. K. Woolf, E. C. Monahan, and D. E. Spiel, "Quantification of the marine aerosol produced by whitecaps," in Preprint, Seventh Conference on Ocean-Atmosphere Interaction (American Meteorological Society, Boston, Mass., 1988), pp. 182-185.

25. E. P. Shettle and R. W. Fenn, Models for the aerosols of the lower atmosphere and the effects of humidity variations on their optical properties, Rep. No. AFGL-TR-79-0214 (Air Force Geophysics Laboratory, Hanscomb Air Force Base, Mass., 1979).

26. A. Mészáros and K. Vissy, "Concentration, size distribution, and chemical nature of atmospheric aerosol particles in remote oceanic areas," Aerosol Sci. 5, 101-109 (1974).

27. M. O. Andreae, "The ocean as a source of atmospheric sulfur compounds," in The Role of Air-Sea Exchange in Geochemical Cycling, P. Buat-Menard, ed. (Reidel, Dordrecht, The Netherlands, 1986), pp. 331-362.

28. R. J. Charlson, J. E. Lovelock, M. O. Andreae, and S. G. Warren, "Oceanic phytoplankton, atmospheric sulphur, cloud albedo and climate," Nature (London) 326, 655-661 (1987).

29. R. A. Duce and A. H. Woodcock, "Difference in chemical composition of atmospheric sea-salt particles produced in the surf zone and on the open sea in Hawaii," Tellus 23, 427-435 (1971).

30. C. S. Wang and R. L. Street, "Measurements of spray at an air-water interface," in Dynamics of Atmospheres and Oceans (Elsevier, Amsterdam, 1978), Vol. 2, pp. 141-152.

31. M. Komabayashi, "Enrichment of inorganic ions with increasing atomic weight in aerosols, rainwater, and snow in comparison with sea water," Meteorol. Soc. Jpn. 40, 25-38 (1962).

32. G. Hänel, "The properties of atmospheric aerosol particles as functions of the relative humidity at thermodynamic equilibrium with the surrounding moist air," Adv. Geophys. 19, 73188 (1976).

33. E. C. Monahan, C. W. Fairall, K. L. Davidson, and P. J. Boyle, "Observed inter-relations between $10 \mathrm{~m}$ winds, ocean whitecaps, and marine aerosols," Q. J. R. Meteorol. Soc. 109, 379392 (1983).

34. V. N. Kapustin and D. S. Covert, "Measurements of the humidification processes of hygroscopic particles," Appl. Opt. 19, 1349-1352 (1980).

35. J. Latham and M. H. Smith, "Effect on global warming of wind-dependent aerosol generation at the ocean surface," Nature (London) 347, 372-373 (1990).

36. S. G. Gathman and K. L. Davidson, "The Navy oceanic vertical aerosol model," Technical Rep. 1634 (Naval Command, Control and Ocean Surveillance Center, San Diego, Calif., 1993).

37. G. M. Hale and M. R. Querry, "Optical constants of water in the 200-nm to 200- $\mu \mathrm{m}$ wavelength region," Appl. Opt. 12, 555563 (1973).

38. F. E. Volz, "Infrared refractive index of atmospheric aerosol substance," Appl. Opt. 11, 755-759 (1972).

39. N. E. Dorsey, Properties of Ordinary Water-Substance in All Its Phases: Water Vapor, Water and All the Ices, Vol. 81 of American Chemical Society Monograph Series (Reinhold, New York, 1940), pp. 332-338.

40. H. C. van de Hulst, Light Scattering by Small Particles (Wiley, New York, 1957).

41. C. F. Bohren and D. R. Huffman, Absorption and Scattering of Light by Small Particles (Wiley, New York, 1983).

42. A. J. Hunt and D. R. Huffman, "A polarization-modulated light scattering instrument for determining liquid aerosol properties,” Jpn. J. Appl. Phys. 14 (Suppl. 14-1), 435-440 (1975).

43. A. C. Holland and G. Gagne, "The scattering of polarized light by polydisperse systems of irregular particles," Appl. Opt. 9, 1113-1121 (1970).

44. K. J. Voss and E. S. Fry, "Measurement of the Mueller matrix for ocean water," Appl. Opt. 23, 4427-4439 (1984).

45. E. S. Fry and K. J. Voss, "Measurement of the Mueller matrix for phytoplankton," Limnol. Oceanogr. 30, 1322-1326 (1985).

46. M. S. Quinby-Hunt, A. J. Hunt, K. Lofftus, and D. B. Shapiro, "Polarized-light scattering studies of marine Chlorella," Limnol. Oceanogr. 34, 1587-1600 (1989).

47. D. R. Huffman, Department of Physics, University of Arizona, Tucson, Ariz., 85721 (personal communication, 1995).

48. E. S. Fry and G. Kattawar, "Relationships between elements of the Stokes matrix," Appl. Opt. 20, 2811-2814 (1981).

49. G. W. Kattawar and E. S. Fry, "Inequalities between the elements of the Mueller scattering matrix: comments" Appl. Opt. 21, 18 (1982).

50. D. Miller, M. S. Quinby-Hunt, and A. J. Hunt, "Laboratory 
studies of the angle and polarization dependent light scattering in sea ice," Appl. Opt. 36, 1278-1288 (1997).

51. D. Miller, M. S. Quinby-Hunt, and A. J. Hunt, "A novel bistatic polarization nephelometer for probing scattering through a planar interface," Rev. Sci. Instrum. 67, 2089-2095 (1997).

52. A. J. Hunt, "An experimental investigation of the angular dependence of polarization of light scattered from small particles," Ph.D. dissertation (University of Arizona, Tucson, Ariz., 1974).

53. A. J. Hunt and D. R. Huffman, "A new polarization-modulated light scattering instrument," Rev. Sci. Instrum. 44, 1753-1762 (1973).

54. X. Quan and E. S. Fry, "Empirical equation for the index of refraction of seawater," Appl. Opt. 34, 3477-3480 (1995).

55. R. M. Garrels and F. T. Mackenzie, Evolution of Sedimentary Rocks (Norton, New York, 1971), p. 212.

56. E. T. Arakawa, M. W. Williams, and T. Inagaki, "Optical properties of arc-evaporated carbon films between 0.6 and $3.8 \mathrm{eV}$," J. Appl. Phys. 48, 3176-3177 (1977).
57. A. B. Pluchino, S. S. Goldberg, J. M. Dowling, and C. M. Randall, "Refractive-index measurements of single micronsized carbon particles," Appl. Opt. 19, 3370-3372 (1980).

58. C. E. Batten, "Spectral optical constants of soots from polarized angular reflectance measurements," Appl. Opt. 24, 11931199 (1985).

59. F. Parungo, B. Kopcewicz, C. Nagamoto, R. Schnell, P. Sheridan, C. Zhu, and J. Harris, "Aerosol particles in the Kuwait oil fire plumes: their morphology, size distribution, chemical composition, transport, and potential effect on climate," J. Geophys. Res. 97, 15,867-15,882 (1992).

60. W. H. Dalzell and A. F. Sarofim, "Optical constants of soot and their application to heat-flux calculations," J. Heat Transfer 91, 100-104 (1969).

61. J. R. Hodkinson, "Refractive index and extinction efficiency factors for carbon," J. Opt. Soc. Am. 54, 846 (1964).

62. V. R. Stull and G. N. Plass, "Emissivity of dispersed carbon particles,” J. Opt. Soc. Am. 50, 121-129 (1960). 